\title{
http://bjas.journals.ekb.eg \\ Impact of Verrucae on Patients' Quality of Life
}

A.A.Ibrahim, R.M.Salem and N.M.El-Araby

Dermatology, Venereology and Andrology Dept., Faculty of Medicine, Benha Univ., Benha, Egypt

E-Mail: nehalmahmoud315@gmail.com

\begin{abstract}
Verruca (Warts) are a typical dermatologic sickness brought about by human papillomavirus (HPV). Verruca are commonly little, harsh, hard papules and skin shaded or slight tanned. Patients with viral moles recorded a more serious negative effect on life quality than patients with different dermatoses, similar to skin break out vulgaris. In this examination, it was planned to explore effect of verrucae on patients' personal satisfaction utilizing Dermatology Life Quality Index (DLQI). This current investigation included 30 patients of verruca vulgaris, palmoplanter moles and genital moles notwithstanding 10 subjects liberated from a verruca as control subjects of coordinated age, sex and BMI of Egyptian starting point. Genital moles had more terrible DLQI than palmoplanter moles, which had more regrettable DLQI than verruca vulgaris $(\mathrm{p}<0.001)$. From this examination we can reason that genital verrucae had the most noticeably awful effect on personal satisfaction when contrasted with other verrucae types.
\end{abstract}

Keywords: Verruca, Dermatological Life Quality Index (DQI).

\section{Introduction}

Viral moles are one of the basic skin issues all in all populace which can influence any age gathering and any sex in any nation and represent a noteworthy medical issue [1].

Cutaneous moles can influence any aspect of the skin yet principally the fingers, the soles, and the face. Inclining conditions for broad or refractory contribution incorporate atopic dermatitis and conditions related with diminished cell-intervened insusceptibility (eg, AIDS [AIDS], organ transplantation) [2].

Sores in the anogenital district are otherwise called condylomata acuminata. They show up as exophytic, cauliflower-like, pedunculated, or expansive based papules or plaques with earthy or skin-hued surface [3].

The Dermatology Life Quality Index as a poll intended for use in grown-ups. The DLQI is determined by adding the score of each question bringing about a limit of 30 and at least 0 . The higher the score, the greater personal satisfaction is impeded [4].

Patients with genital moles apply serious negative effect on life quality and mental condition of the influenced ladies [5].

In the other hand, different examinations showed that patients with extra-genital moles have more noteworthy hindrance of patients' life quality in contrast with patients with genital moles in Egyptian patients [6].

In this examination, it was planned to research effect of verrucae on patients' personal satisfaction utilizing Dermatology Life Quality Index (DLQI).

\section{Patients and methods}

This is a cross Section case control study .The examination included thirty patients with verruca vulgaris, palmoplanter moles and genital moles and ten solid subjects, age and sex coordinated, going to the dermatology outpatient facility at Benha University Hospital, Benha, Egypt.

Members gave their educated composed assent before enlistment and the investigation was endorsed by the Research Ethics Committee in Faculty of Medicine, Benha University.

All patients remembered for the investigation have kinds of moles. Patients with skin malady other than moles and subjects with intense or incessant contaminations, malignancies, immune system issues, hepatic or renal infections were rejected.

None of the patients was on foundational or skin treatment for one month before the examination. Verruca was analyzed clinically.

\section{Effect of moles on DLQI}

The DLQI is determined by adding the score of each question bringing about a limit of 30 and at least 0 . The higher the score, the greater personal satisfaction is weakened.

\section{How to interpret scoring}

- $0-1$ no effect at all on patient's life.

- $2-5$ small effect on patient's life.

- 6-10 moderate effect on patient's life.

- $11-20$ very large effect on patient's life.

- 21 - 30 extremely large effect on patient's life.

\subsection{Statistical analysis}

Statistical analysis was performed using the Statistical Package for Social Sciences (SPSS) vs.25. Mean $\pm S D$, t test, Mann Whitney test, Chi square test, Pearson test, Kruskal Wallis test, ROC and AUC, were used.

\section{Results}

1- Demographic data of patients groups and controls

There was also insignificant differences between different patients groups regarding age and gender $(\mathrm{p}=0.365,0.899$ respectively) Table (1). 
Table (1) Demographic data of patients groups.

\begin{tabular}{|c|c|c|c|c|c|c|c|c|c|c|}
\hline \multirow[b]{3}{*}{ Age (years) } & \multirow[b]{3}{*}{ mean $\pm \mathrm{SD}$} & \multirow{2}{*}{\multicolumn{2}{|c|}{$\begin{array}{c}\begin{array}{c}\text { Verruca } \\
\text { vulgaris }\end{array} \\
\mathbf{N}=\mathbf{1 0} \\
\end{array}$}} & \multirow{2}{*}{\multicolumn{2}{|c|}{$\begin{array}{c}\begin{array}{c}\text { Palmo planter } \\
\text { warts }\end{array} \\
\mathrm{N}=10 \\
\end{array}$}} & \multirow{2}{*}{\multicolumn{2}{|c|}{$\begin{array}{c}\text { Genital warts } \\
\mathrm{N}=10\end{array}$}} & \multirow{2}{*}{\multicolumn{2}{|c|}{$\begin{array}{c}\text { Control } \\
\mathbf{N}=10 \\
\end{array}$}} & \multirow{3}{*}{$\begin{array}{c}\mathbf{p} \\
0.362\end{array}$} \\
\hline & & & & & & & & & & \\
\hline & & 27.7 & 8.6 & 32.3 & 10.4 & 34.3 & 7.1 & 27.9 & 9.3 & \\
\hline Males & $\mathrm{N}, \%$ & 7 & $70 \%$ & 5 & $50 \%$ & 6 & $60 \%$ & 5 & $50 \%$ & \multirow{2}{*}{0.899} \\
\hline Females & $\mathrm{N}, \%$ & 3 & $30 \%$ & 5 & $50 \%$ & 4 & $40 \%$ & 5 & $50 \%$ & \\
\hline
\end{tabular}

2- Impact on quality of life

Dermatology quality of life was assessed in all studied cases. Mean DLQI was 11.1 \pm 3.2 . Mean DLQI in VV was 4.2, in PP was 5.6, in GW was 23.5. Genital warts had worse DQI than palmoplanter warts, which had worse DLQI than verruca vulgaris $(\mathrm{p}<0.001)$ Fig (1).

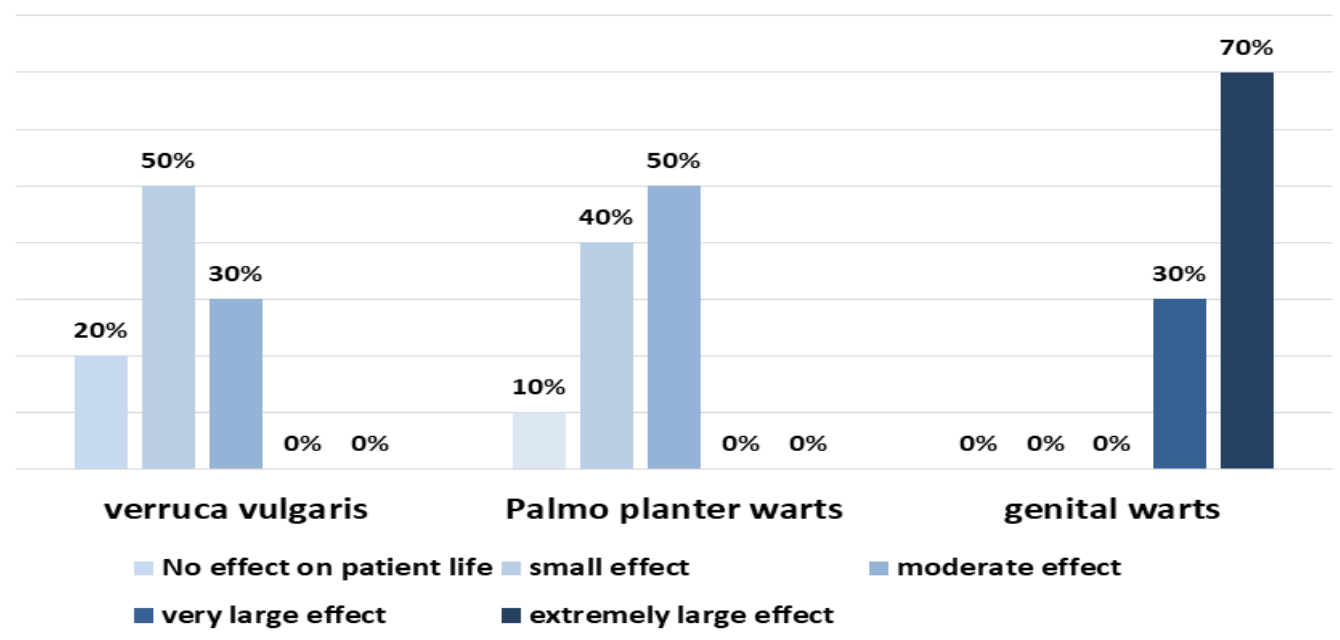

Fig (1) DLQI among all studied cases.

\section{Discussion}

Moles are basic viral skin contaminations, influencing around $7-12 \%$ of the populace at any one time, and are more normal in kids. They are brought about by the human papilloma infection (HPV), of which there are more than 150 genotypically various sorts [7] .

There are numerous clinical introductions of moles including verruca vulgaris, periungual and subungual verruca, plantar moles, plane moles and filiform moles [8].

Patients with viral moles recorded a more serious negative effect on life quality than patients with different dermatoses, similar to skin inflammation vulgaris [4].

About $81.4 \%$ of ladies were concerned, restless and discouraged, $54.3 \%$ felt agony and inconvenience in the genital area, and $57.7 \%$ experienced tingling and copying. Disgrace and uncertainty were accounted for by $64.8 \%$ of patients. About $50.7 \%$ had an issue with genital moles that influenced their relationship, while $62.1 \%$ had issues with sex [5] .

Extra-genital moles have a solid negative effect on patients' day by day life. In this manner, strongly proposals considered the unsafe impacts of extragenital moles on patients' personal satisfaction. The treating doctors should utilize the "bio-psycho-social" model when confronting patients with extra-genital moles trying to make sure about the best life quality. [6]

Consequences of the current investigation demonstrated that there was huge connection between's Dermatology Life Quality Index scores in the examined cases.

\section{Conclusion}

From this study we can conclude that genital verrucae had the worst impact on quality of life when compared to other verrucae types.

Financial support and sponsorship Nil.

\section{Conflicts of interest}

There are no conflicts of interest.

\section{Reference}

[1] A.Ranjit, S.L.Rajbhandari, N.Gautam, Y. Poudyal. Association between Serum Zinc Level and Cutaneous Viral Warts: A Case Control Study. Nepal Journal of Dermatology, Venereology \& Leprology, Vol.17 (1), PP.17-21, 2019.

[2] M.A. Karam, H.A. Al-Hmudi. Genotyping of Human Papillomavirus (HPV) from Patients with 
Cutaneous Warts. Sci. J. Med. Res, Vol.3(11), PP.107-112.N, 2019..

[3] A.Arshad, S.Younas, T.J.Ahmed, T. Rashid. Nadeem. Outcome of $20 \%$ topical zinc oxide ointment in the treatment of cutaneous warts of hands and feet. Journal of Fatima Jinnah Medical University,Vol.13(1), PP.23-25, 2019.

[4] A.Y.Finlay , G. Khan. Dermatology Life Quality Index (DLQI) - a simple practical measure for routine clinical use. Clinical and experimental dermatology, Vol.19(3), PP.210-216, 1994.

[5] L. Mladenović-Segedi and A. Bjelica. The quality of life of women with genital warts. Medicinski pregled, Vol.72(3-4), PP.61-65, 2019.
[6] E. Salah. Impact of multiple extragenital warts on quality of life in immune-competent Egyptian adults: a comparative cross-sectional study. Clinical, cosmetic and investigational dermatology, Vol.11, PP.289, 2018.

[7] S.A. Ringin. The effectiveness of cutaneous wart resolution with current treatment modalities. Journal of Cutaneous and Aesthetic Surgery, Vol.13(1), PP.24, 2020.

[8] D.Abeck, L.Tetsch, M. Lüftl, T. Biedermann. Extragenital cutaneous warts-clinical presentation, diagnosis and treatment. JDDG: Journal der Deutschen Dermatologischen Gesellschaft, Vol.17(6), PP.613-634, 2019. 